\title{
A Fuzzy AHP Approach for Supplier Selection
}

\author{
Abhijeet K. Digalwar \\ Mechanical Engineering Department, BITS Pilani, India \\ E-mail: akd@pilani.bits-pilani.ac.in
}

\author{
Atul Borade \\ Mechanical Engineering Department, JDIET Yavatmal, India \\ E-mail: atulborade@rediffmail.com
}

\author{
Bhimaraya Metri \\ IMI New Delhi, India \\ E-mail: metri@imi.edu (Corresponding Author)
}

\begin{abstract}
Supplier selection is an integral part of supply chain management in any organization which is directly responsible for its success in market and if we see today's highly competitive environment then it is pretty much difficult to find an effective and efficient supplier which can fulfill all organization's need as required. Though there has been extensive research in supplier selection and quality management, but there has been less research in supplier selection/ evaluation under various conflicting/dependent criteria and sub criteria. To overcome this issue, Fuzzy-AHP a multi criteria decision making approach is proposed. This allows the decision making in fuzzy environment to rule out the error caused due to vagueness in human thoughts.
\end{abstract}

Keywords: supplier selection, MCDM, AHP, fuzzy

\section{INTRODUCTION}

Varieties of customer demands, advances of information technologies, competition in global environment, increases in governmental regulations and in environmental consciousness have forced companies for focusing on supply chain management. The supply chain management term has been used from almost two decades and is defined as the integration of activities to procure materials, transforms them into intermediate goods and final products, and delivers to customers. The supply chain consists of all links from suppliers to customers of a product. Many researchers (Tracey and Tan, 2001; De Boer et al., 2001; Bello, 2003; Cebi and Bayraktar, 2003; Digalwar and Metri, 2005; Digalwar and Sangwan, 2007; Calvi et al. 2010; Chen et al., 2011; Lee et al. 2012; Abadi and Cordon, 2012) have stated that supplier management is one of the key issues of supply chain management and business excellence because the cost of raw materials and component parts constitutes the main cost of a product and most of the firms have to spend considerable amount of their sales revenues on purchasing. Hence, supplier selection is one of the most important decision making problems, since selecting the right suppliers significantly reduces the purchasing costs and improves corporate competitiveness (Cebi and Bayraktar, 2003).

On the other hand, supplier selection decision-making problem involves trade-offs among multiple criteria that involve both quantitative and qualitative factors, which may also be conflicting. Now a day, buyer-supplier relationships based on the price factor has not been appropriate in supply chain management. Considerations have been given also to the other important strategic and operational factors such as quality, delivery, flexibility, service, time etc. Supplier selection decisions must include strategic and operational factors as well as tangible and intangible factors in the analysis. Hence, supplier selection problem can be modeled and solved by means of utilizing multi-criteria decision analysis (MCDA).

There are several supplier selection methods available in the literature. Many researchers (Yang and Chen, 2006; Kirytopoulos, 2008; Koul and Verma, 2011; Singh and Sharma, 2011; Khaled et al., 2011;Singh et al., 2011; Sennaroglu and Sen, 2012; Kumar and Singh, 2012; Mukherjee and Kar, 2012) used different MADM approaches for the selection of best supplier. Some authors proposed linear weighting models in which suppliers are rated on several criteria and in which these ratings are combined into a single score. These models include the categorical, the weighted point and the analytical hierarchical process. Total cost approaches attempt to quantify all costs related to the selection of a vendor in monetary units, this approach includes cost ratio and total cost of ownership. Mathematical programming models often consider only the more quantitative criteria; this approach includes the principal component analysis and neural network. The categorical method relies heavily on the experience and ability of the individual buyer. People in charge of purchasing, quality, production, and sales all express their opinions about the supplier's performance on the basis criteria which are important to them. These departments assign either a preferred, unsatisfactory, or neutral rating for each of the selected attributes for every contending supplier. At periodic evaluation meetings, the buyer discusses the rating with department members. The buyer then determines the supplier's overall scores. The primary advantage of the categorical approach is that it helps structure the evaluation process in a clear and systematic way. This method is quite simple, it is not supported by objective criteria, and rarely leads to performance improvements. The main drawback of this method is that the identified attributes are weighted equally 
Digalwar et al. : A Fuzzy AHP Approach for Supplier Selection

Operations and Supply Chain Management 7 (2) pp. 46 - 53 () 2014

Table 1 Linguistic variables for the importance weight of each criteria

\begin{tabular}{|c|c|c|c|c|c|}
\hline Rank & $\begin{array}{c}\text { Sub-Criteria } \\
\text { Grade }\end{array}$ & Membership Function & Rank & $\begin{array}{c}\text { Sub-Criteria } \\
\text { Grade }\end{array}$ & Membership Function \\
\hline Very Low (VL) & 1 & $(0.00,0.10,0.25)$ & High $(\mathrm{H})$ & 4 & $(0.55,0.70,0.85)$ \\
\hline Low (L) & 2 & $(0.15,0.30,0.45)$ & Very High $(\mathrm{VH})$ & 5 & $(0.75,0.90,1.0)$ \\
\hline Medium (M) & 3 & $(0.35,0.50,0.65)$ & &
\end{tabular}

and the decisions made using this system tend to be fairly subjective (Bello, 2003).

One drawback of above approaches is that they don't consider the case of supplier selection while dependent criteria and sub criteria are involved. Most of the times decision makers choose suppliers on their experience and intuitiveness which becomes completely vague. This paper takes a step forward from subjective approaches to the mathematical model using a fuzzy-AHP approach to overcome this issue.

\section{FUZZY-AHP METHOD}

\subsection{Fuzzy Logic}

The Fuzzy Logic tool was introduced by Lotfi Zadeh in 1965. It is a mathematical tool for dealing with uncertainty. It offers soft computing partnership to the important concept of computing with words'. It provides a technique to deal with imprecision and information granularity. The fuzzy theory provides a mechanism for representing linguistic constructs such as "many," "low," "medium," "often," "few." In general, the fuzzy logic provides an inference structure that enables appropriate human reasoning capabilities. On the contrary, the traditional binary set theory describes crisp events, events that either do or do not occur. It uses probability theory to explain if an event will occur, measuring the chance with which a given event is expected to occur. The theory of fuzzy logic is based upon the notion of relative graded membership and so is the function of cognitive process.

The utility of fuzzy sets lies in their ability to model uncertain or ambiguous data. As the complexity of a task, or of a system for performing that task, exceeds a certain threshold, the system must necessarily become fuzzy in nature. Zadeh, originally an engineer and systems scientist, was concerned with the rapid decline in information afforded by traditional mathematical models as the complexity of the target system increased. Real world problems are too complex, and the complexity involves the degree of uncertainty - as uncertainty increases, so does the complexity of the problem. Traditional system modeling and analysis techniques are too precise for such problems, In this aspect, fuzzy systems theory is similar to other engineering theories, because almost all of them characterize the real world in an approximate manner (Sivanandam et al. 2007).

Experts usually use the linguistic variable to evaluate the importance of the criteria and to rate the alternatives with respect to various criteria. The example of the present study has only precise values for the performance ratings and for the criteria weights. In order to illustrate the idea of Fuzzy MADM, we deliberately transform the existing precise values to five levels, Fuzzy linguistic variables very low (VL), low (L), medium (M), high $(\mathrm{H})$, and very high $(\mathrm{VH})$. The purpose of the transformation process is two- folded: (i) to illustrate the proposed Fuzzy MADM method and (ii) to benchmark the empirical results using other precise value methods in the later analysis.

Among the commonly used Fuzzy numbers, triangular and trapezoidal fuzzy numbers are likely to be the adoptive ones due to their simplicity in modeling easy interpretations. Both triangular and trapezoidal fuzzy numbers are applicable to the present study. The present work assume that a triangular fuzzy number (TFN), it is a fuzzy number represented with three points (a1, a2, a3) and can adequately represent the five-level Fuzzy linguistic variables, thus, is used for the analysis hereafter.

As a rule of thumb, each rank is assigned an evenly spread membership function that has an interval of 0.30 or 0.25 . Based on these assumptions, a transformation table is shown below. For example, the Fuzzy variable, very low has its associated triangular Fuzzy number with the minimum of 0.00 mode of 0.10 and maximum of 0.25 . The same definition is then applied to another Fuzzy variable Low, Medium, High, and Very High. Table 1 illustrates the Fuzzy membership function.

\subsection{AHP Methodology}

The analytic hierarchy process (AHP), introduced by Saaty (1977), is a theory of measurement that provides the ability to incorporate both qualitative and quantitative factors in the decision making process. It facilitates decision making by organizing perceptions, feelings, judgments and memories into a multi-level hierarchic structure that exhibits the forces that influence a decision. The AHP procedure begins with the development of a hierarchical structure of a supplier selection problem. Once the hierarchy has been constructed, he decision makers evaluate the elements by making pairwise comparisons. In AHP, pairwise comparison matrices, based on comparing the relative importance or preferences of two elements with respect to element in the level above, are generated by verbal judgments such as high, medium and low or by stating a single number taken from the 1-9 comparison scale.

\section{AHP steps are defined as follows:}

Step 1: AHP uses several small sub-problems to present a complex decision problem. Thus, the first act is to decompose the decision problem into a hierarchy with a goal at the top, criteria and sub-criteria at levels and sub-levels and decision alternatives at the bottom of the hierarchy.

Step 2: The comparison matrix involves the comparison in pairs of the elements of the constructed hierarchy. The aim is to set their relative priorities with respect to each of the elements at the next higher level. It appears that the weight determination of criteria is more reliable when using pairwise comparisons than obtaining them directly, because 


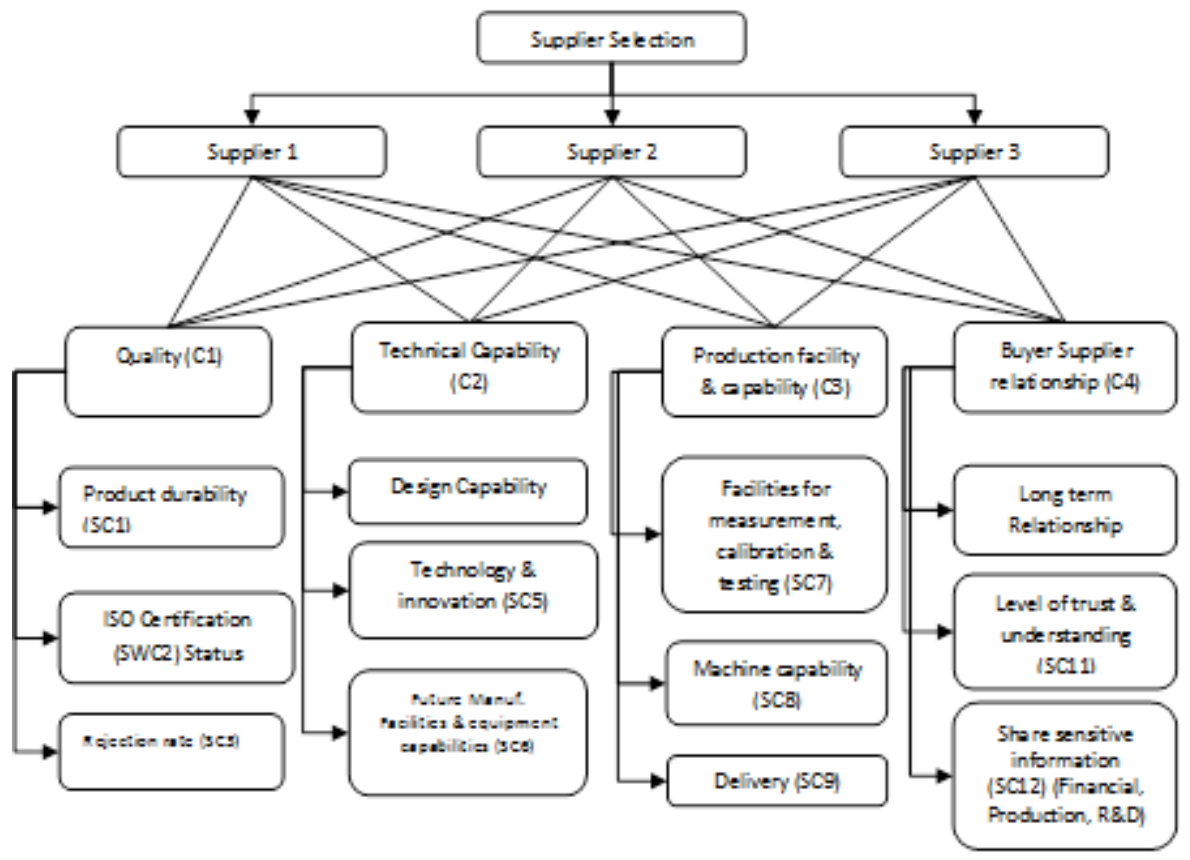

Figure 1 The Hierarchical Structure of Decision Problem

it is easier to make a comparison between two attributes than make an overall weight assignment. So to assign weights we use [1,9] numbers with 1 being equal importance and 9 being that ith criteria is nine times more important than jth one and likewise. And reciprocal of number will indicate jth is of more importance.

Step 3: In the next step, transform the real elements of matrix R into the fuzzy numbers.

Step 4: Before conducting all the calculation of vector of priorities, the comparison matrix D has to be normalized.

Step 5: To find the criteria weights, calculate the average of the elements of each rows from matrix obtained from step 4.

Step 6: Finally rank the criteria according to do fuzzy comparison of sets by seeing the average of each element obtained in step 5 .

\subsection{Case Study}

The paper presents the numerical method for supplier selection for braking system material. A manufacturing company desires to select a most suitable supplier for its product Anti-compounding relay valve (ACRV).
Management of organization has decided the criteria quality, technical capability, production facility and capability, buyer-supplier relationship. Sub criteria are Product Durability, ISO Certification status, Rejection Rate, Design Capability, Technology and innovation, Future manufacturing facilities and equipment capabilities, Facilities for measurement, calibration and testing, Machine capability, Delivery, Long-term Relationship, Level of trust and understanding, Share sensitive information (financial, production, $R \& D$ ) for the evaluation of their suppliers. The hierarchical structure of this decision problem is shown in Figure 1. As mentioned, the AHP methodology first necessitates the pairwise comparisons of the criteria and subcriteria in order to determine their weights. These consistent comparison matrices are shown in Table 2. The normalized priority weights among the two main criteria and five subcriteria and their ranking have been depicted in Table 3 as shown below.

Normalized AHP weights (Table 3) are converted into fuzzy linguistic variables (Table 4 and 5) using Table 1. And then average of each row is obtained for each criterion as shown in Table 5. This will decide the comparative raking of each criterion - sub criteria

Table 2 AHP Weight

\begin{tabular}{|c|c|c|c|c|c|c|c|c|c|c|c|c|c|c|c|c|}
\hline & $\mathrm{Cl}$ & 0 & C & a & SCI & SC2 & so & $\mathrm{SCA}$ & SC5 & $5 C 6$ & SC7 & $5 \mathrm{CB}$ & 500 & $5 \mathrm{C} 10$ & $5 \mathrm{Cl1}$ & SC12 \\
\hline C1 & 1 & 3 & 5 & & $6-$ & - & - & - & - & - & - & - & - & - & - & - \\
\hline C2 & 0.333 & 1 & 4 & 7 & - & - & - & - & - & - & - & - & - & - & - & - \\
\hline C3 & 0.2 & 0.25 & 1 & 0.333 & & - & - & - & - & - & - & - & - & - & - & - \\
\hline$C 4$ & 0.167 & 0.143 & 3 & & $1-$ & - & - & - & - & - & - & - & - & - & - & - \\
\hline SCI & - & - & - & - & 1 & 0.143 & 0.2 & 1 & 1 & 5 & 3 & 5 & 0.333 & 2 & 3 & 0.25 \\
\hline $5 \mathrm{C} 2$ & - & - & - & - & 7 & 1 & 5 & 6 & 4 & 7 & 8 & 3 & 6 & 4 & 5 & 2 \\
\hline $5 \mathrm{C3}$ & - & - & - & - & 5 & 0.2 & 1 & 6 & 5 & 3 & 6 & 5 & 3 & 4 & 5 & 4 \\
\hline SCA & - & - & - & - & 1 & 0.167 & 0.167 & 1 & 1 & 4 & 6 & 4 & 2 & 3 & 4 & 2 \\
\hline SC5 & - & - & - & - & 1 & 0.25 & 0.2 & 1 & 1 & 4 & 5 & 3 & 2 & 3 & 3 & 2 \\
\hline 506 & - & - & - & - & 0.2 & 0.143 & 0.333 & 0.25 & 0.25 & 1 & 4 & 3 & 2 & 4 & 3 & 2 \\
\hline $5 \mathrm{C} 7$ & - & - & - & - & 0.33 & 0.13 & 0.17 & 0.17 & 0.20 & 0.25 & 1 & 0.33 & 0.17 & 0.25 & 0.20 & 0.14 \\
\hline $5 \mathrm{CB}$ & - & - & - & - & 0.20 & 0.33 & 0.20 & 0.25 & 0.33 & 0.33 & 3 & 1 & 0.25 & 0.25 & 0.20 & 0.17 \\
\hline
\end{tabular}


Digalwar et al.: A Fuzzy AHP Approach for Supplier Selection

Operations and Supply Chain Management 7 (2) pp. 46 - 53 () 2014

Table 2 AHP Weight (contd.)

\begin{tabular}{|c|c|c|l|l|l|l|l|l|l|l|l|l|l|l|c|c|}
\hline & Cl & Q & C & G & SC1 & SC2 & SO & SC4 & SC5 & 5C6 & SC7 & 5C8 & $5 C 9$ & 5C10 & 5C11 & SC12 \\
\hline SC9 & - & - & - & - & 3.00 & 0.17 & 0.33 & 0.50 & 0.50 & 0.50 & 6 & 4 & 1 & 6 & 4 & 3 \\
\hline SC10 & - & - & - & - & 0.50 & 0.25 & 0.25 & 0.33 & 0.33 & 0.25 & 4 & 4 & 0.17 & 1 & 0.20 & 0.25 \\
\hline 5011 & - & - & - & - & 0.33 & 0.20 & 0.20 & 0.25 & 0.33 & 0.33 & 5 & 5 & 0.25 & 5 & 1 & 0.33 \\
\hline $5 C 12$ & - & - & - & - & 4.00 & 0.50 & 0.25 & 0.50 & 0.50 & 0.50 & 7 & 6 & 0.33 & 4 & 3 & 1 \\
\hline
\end{tabular}

Table 3 Normalized AHP Weight

\begin{tabular}{|c|c|c|c|c|c|c|c|c|c|c|c|c|c|c|c|c|}
\hline & Cl & C2 & C3 & C4 & SC1 & SC2 & SC3 & SC4 & SC5 & SC6 & SC7 & SC8 & SC9 & SC10 & SC11 & SC12 \\
\hline CI & 0.59 & 0.68 & 0.38 & 0.42 & - & - & - & - & - & - & - & - & - & - & - & - \\
\hline C2 & 0.20 & 0.23 & 0.31 & 0.49 & - & - & - & - & - & - & - & - & - & - & - & - \\
\hline C3 & 0.12 & 0.06 & 0.08 & 0.02 & - & - & - & - & - & - & - & - & - & - & - & - \\
\hline C4 & 0.10 & 0.03 & 0.23 & 0.07 & - & - & - & - & - & - & - & - & - & - & - & - \\
\hline SC1 & - & - & - & - & 0.04 & 0.04 & 0.02 & 0.06 & 0.07 & 0.19 & 0.05 & 0.12 & 0.02 & 0.05 & 0.09 & 0.01 \\
\hline SC2 & - & - & - & - & 0.30 & 0.29 & 0.60 & 0.35 & 0.28 & 0.27 & 0.14 & 0.07 & 0.34 & 0.11 & 0.16 & 0.12 \\
\hline SC3 & - & - & - & - & 0.21 & 0.06 & 0.12 & 0.35 & 0.35 & 0.11 & 0.10 & 0.12 & 0.17 & 0.11 & 0.16 & 0.23 \\
\hline SC4 & - & - & - & - & 0.04 & 0.05 & 0.02 & 0.06 & 0.07 & 0.15 & 0.10 & 0.09 & 0.11 & 0.08 & 0.13 & 0.12 \\
\hline SC5 & - & - & - & - & 0.04 & 0.07 & 0.02 & 0.06 & 0.07 & 0.15 & 0.09 & 0.07 & 0.11 & 0.08 & 0.09 & 0.12 \\
\hline SC6 & - & - & - & - & 0.01 & 0.04 & 0.04 & 0.01 & 0.02 & 0.04 & 0.07 & 0.07 & 0.11 & 0.11 & 0.09 & 0.12 \\
\hline SC7 & - & - & - & - & 0.01 & 0.04 & 0.02 & 0.01 & 0.01 & 0.01 & 0.02 & 0.01 & 0.01 & 0.01 & 0.01 & 0.01 \\
\hline SC8 & - & - & - & - & 0.01 & 0.10 & 0.02 & 0.01 & 0.02 & 0.01 & 0.05 & 0.02 & 0.01 & 0.01 & 0.01 & 0.01 \\
\hline SC9 & - & - & - & - & 0.13 & 0.05 & 0.04 & 0.03 & 0.03 & 0.02 & 0.10 & 0.09 & 0.06 & 0.16 & 0.13 & 0.18 \\
\hline SC10 & - & - & - & - & 0.02 & 0.07 & 0.03 & 0.02 & 0.02 & 0.01 & 0.07 & 0.09 & 0.01 & 0.03 & 0.01 & 0.01 \\
\hline SC11 & - & - & - & - & 0.01 & 0.06 & 0.02 & 0.01 & 0.02 & 0.01 & 0.09 & 0.12 & 0.01 & 0.14 & 0.03 & 0.02 \\
\hline SC12 & - & - & - & - & 0.17 & 0.14 & 0.03 & 0.03 & 0.03 & 0.02 & 0.12 & 0.14 & 0.02 & 0.11 & 0.09 & 0.06 \\
\hline
\end{tabular}

Table 4 Fuzzy Transformation of Normalized Weight

\begin{tabular}{|c|c|c|c|c|c|c|c|c|c|c|c|c|c|c|c|c|}
\hline & C1 & $U$ & C3 & C4 & SC1 & SC2 & SC3 & SC4 & SC5 & SC6 & SC7 & SC8 & SC9 & SC10 & SC11 & $\mathrm{SC} 12$ \\
\hline C1 & $\mathrm{H}$ & $\mathrm{H}$ & I. & I. & - & - & - & - & - & - & - & - & - & - & - & - \\
\hline C2 & I. & $\mathrm{I}$. & I. & $M$ & - & - & - & - & - & - & - & - & - & - & - & - \\
\hline C3 & Vl. & VI. & VI. & VI. & - & - & - & - & - & - & - & - & - & - & - & - \\
\hline C4 & VI. & VI. & I. & VI. & - & - & - & - & - & - & - & - & - & - & - & - \\
\hline SC1 & - & - & - & - & VI. & VI. & VI. & VI. & VI. & VI. & VI. & VI. & VI. & VI. & VI. & VI. \\
\hline SC2 & - & - & - & - & $\mathrm{I}$. & I. & $M$ & I. & I. & I. & VI. & VI. & I. & VI. & VI. & VI. \\
\hline $\mathrm{SC} 3$ & - & - & - & - & I. & VI. & I. & I. & I. & VI. & VI. & VI. & VI. & VI. & VI. & VI. \\
\hline SC4 & - & - & - & - & VI. & VI. & VI. & VI. & VI. & Vl. & VI. & VI. & VI. & VI. & VI. & VI. \\
\hline SCS & - & - & - & - & VI. & VI. & VI. & VI. & VI. & VI. & VI. & VI. & VI. & VI. & VI. & VI. \\
\hline SC6 & - & - & - & - & VI. & VI. & VI. & VI. & VI. & VI. & VI. & VI. & VI. & VI. & VI. & VI. \\
\hline SC7 & - & - & - & - & VI. & VI. & VI. & VI. & VI. & VI. & VI. & VI. & VI. & VI. & VI. & VI. \\
\hline SC8 & - & - & - & - & VI. & VI. & VI. & VI. & VI. & VI. & VI. & VI. & VI. & VI. & VI. & VI. \\
\hline $\mathrm{SC} 9$ & - & - & - & - & VI. & VI. & VI. & VI. & VI. & VI. & VI. & VI. & VI. & VI. & VI. & VI. \\
\hline SC10 & - & - & - & - & VI. & VI. & VI. & VI. & VI. & VI. & VI. & VI. & VI. & VI. & VI. & VI. \\
\hline SC11 & - & - & - & - & VI. & VI. & VI. & VI. & VI. & VI. & VI. & VI. & VI. & VI. & VI. & VI. \\
\hline SC12 & - & - & - & - & VI. & I. & VI. & VI. & VI. & VI. & VI. & VI. & VI. & VI. & VI. & VI. \\
\hline
\end{tabular}


Digalwar et al. : A Fuzzy AHP Approach for Supplier Selection

Table 5 Fuzzy Linguistic Variables of Normalized Weight

\begin{tabular}{|c|c|c|c|c|c|c|c|c|c|}
\hline & $\mathrm{Cl}$ & $\mathrm{C} 2$ & $\mathrm{C} 3$ & $\mathrm{C} 4$ & SC1 & SC2 & $\mathrm{SC} 3$ & SC4 & SC5 \\
\hline $\mathrm{Cl}$ & $(0.55,0.70,0.85)$ & $(0.55,0.70,0.85)$ & $(0.15,0.30,0.45)$ & $(0.15,0.30,0.45)$ & - & - & - & - & - \\
\hline $\mathrm{C} 2$ & $(0.15,0.30,0.45)$ & $(0.15,0.30,0.45)$ & $(0.15,0.30,0.45)$ & $(0.35,0.50,0.65)$ & - & - & - & - & - \\
\hline C3 & $(0.0,0.10,0.2)$ & $(0.0,0.10,0.25)$ & $(0.0,0.10,0.25)$ & $(0.0,0.10,0.25)$ & - & - & - & - & - \\
\hline C4 & $(0.0,0.10,0.25)$ & $(0.0,0.10,0.25)$ & $(0.15,0.30,0.45)$ & $(0.0,0.10,0.25)$ & - & - & - & - & - \\
\hline SC1 & - & - & - & - & $(0.0,0.10,0.25)$ & $(0.0,0.10,0.25)$ & $(0.0,0.10,0.25)$ & $(0.0,0.10,0.25)$ & $(0.0,0.10,0.25)$ \\
\hline $\mathrm{SC2}$ & - & - & - & - & $(0.15,0.30,0.45)$ & $(0.15,0.30,0.4 \mathrm{E}$ & $(0.35,0.50,0.65)$ & $(0.15,0.30,0.45)$ & $(0.15,0.30,0.45)$ \\
\hline $\mathrm{SC} 3$ & - & - & - & - & $(0.0,0.10,0.25)$ & $(0.0,0.10,0.25)$ & $(0.15,0.30,0.45)$ & $(0.15,0.30,0.45)$ & $(0.15,0.30,0.45)$ \\
\hline $\mathrm{SC} 4$ & - & - & - & - & $(0.0,0.10,0.25)$ & $(0.0,0.10,0.25)$ & $(0.0,0.10,0.25)$ & $(0.0,0.10,0.25)$ & $(0.0,0.10,0.25)$ \\
\hline SC5 & - & - & - & - & $(0.0,0.10,0.25)$ & $(0.0,0.10,0.25)$ & $(0.0,0.10,0.25)$ & $(0.0,0.10,0.25)$ & $(0.0,0.10,0.25)$ \\
\hline SC6 & - & - & - & - & $(0.0,0.10,0.25)$ & $(0.0,0.10,0.25)$ & $(0.0,0.10,0.25)$ & $(0.0,0.10,0.25)$ & $(0.0,0.10,0.25)$ \\
\hline SC7 & - & - & - & - & $(0.0,0.10,0.25)$ & $(0.0,0.10,0.25)$ & $(0.0,0.10,0.25)$ & $(0.0,0.10,0.25)$ & $(0.0,0.10,0.25)$ \\
\hline SC8 & - & - & - & - & $(0.0,0.10,0.25)$ & $(0.0,0.10,0.25)$ & $(0.0,0.10,0.25)$ & $(0.0,0.10,0.25)$ & $(0.0,0.10,0.25)$ \\
\hline Sc9 & - & - & - & - & $(0.0,0.10,0.25)$ & $(0.0,0.10,0.25)$ & $(0.0,0.10,0.25)$ & $(0.0,0.10,0.25)$ & $(0.0,0.10,0.25)$ \\
\hline SC10 & - & - & - & - & $(0.0,0.10,0.25)$ & $(0.0,0.10,0.25)$ & $(0.0,0.10,0.25)$ & $(0.0,0.10,0.25)$ & $(0.0,0.10,0.25)$ \\
\hline SC11 & - & - & - & - & $(0.0,0.10,0.25)$ & $(0.0,0.10,0.25)$ & $(0.0,0.10,0.25)$ & $(0.0,0.10,0.25)$ & $(0.0,0.10,0.25)$ \\
\hline $\mathrm{SC} 12$ & - & - & - & - & $(0.0,0.10,0.25)$ & $(0.15,0.30,0.4 \mathrm{E}$ & $(0.0,0.10,0.25)$ & $(0.0,0.10,0.25)$ & $(0.0,0.10,0.25)$ \\
\hline
\end{tabular}


Digalwar et al. : A Fuzzy AHP Approach for Supplier Selection

Operations and Supply Chain Management 7 (2) pp. 46 - 53 (C) 2014

Table 5 Fuzzy Linguistic Variables of Normalized Weight (Contd.)

\begin{tabular}{|c|c|c|c|c|c|c|c|c|}
\hline Sc6 & SC7 & SC8 & SC9 & SC10 & SC11 & $\mathrm{SC} 12$ & Average(W) & Rank® \\
\hline- & - & - & - & - & - & - & $(0.35,0.50,0.65)$ & 1 \\
\hline- & - & - & - & - & - & - & $(0.20,0.35,0.50)$ & 2 \\
\hline- & - & - & - & - & - & - & $(0.0,0.10,0.25)$ & 4 \\
\hline- & - & - & - & - & - & - & $(0.0,0.15,0.0 .4)$ & 3 \\
\hline$(0.0,0.10,0.25)$ & $(0.0,0.10,0.25)$ & $(0.0,0.10,0.25)$ & $(0.0,0.10,0.25)$ & $(0.0,0.10,0.25)$ & $(0.0,0.10,0.25)$ & $(0.0,0.10,0.25)$ & $(0.0,0.10,0.25)$ & 4 \\
\hline$(0.15,0.30,0.45)$ & $(0.0,0.10,0.25)$ & $(0.0,0.10,0.25)$ & $(0.15,0.30,0.45)$ & $(0.0,0.10,0.25)$ & $(0.0,0.10,0.25)$ & $(0.0,0.10,0.25)$ & $(0.10,0.23,0.38)$ & 3. \\
\hline$(0.0,0.10,0.25)$ & $(0.0,0.10,0.25)$ & $(0.0,0.10,0.25)$ & $(0.0,0.10,0.25)$ & $(0.0,0.10,0.25)$ & $(0.0,0.10,0.25)$ & $(0.0,0.10,0.25)$ & $(0.03,0.15,0.30)$ & 2 \\
\hline$(0.0,0.10,0.25)$ & $(0.0,0.10,0.25)$ & $(0.0,0.10,0.25)$ & $(0.0,0.10,0.25)$ & $(0.0,0.10,0.25)$ & $(0.0,0.10,0.25)$ & $(0.0,0.10,0.25)$ & $(0.0,0.10,0.25)$ & 4 \\
\hline$(0.0,0.10,0.25)$ & $(0.0,0.10,0.25)$ & $(0.0,0.10,0.25)$ & $(0.0,0.10,0.25)$ & $(0.0,0.10,0.25)$ & $(0.0,0.10,0.25)$ & $(0.0,0.10,0.25)$ & $(0.0,0.10,0.25)$ & 4 \\
\hline$(0.0,0.10,0.25)$ & $(0.0,0.10,0.25)$ & $(0.0,0.10,0.25)$ & $(0.0,0.10,0.25)$ & $(0.0,0.10,0.25)$ & $(0.0,0.10,0.25)$ & $(0.0,0.10,0.25)$ & $(0.0,0.10,0.25)$ & 4 \\
\hline$(0.0,0.10,0.25)$ & $(0.0,0.10,0.25)$ & $(0.0,0.10,0.25)$ & $(0.0,0.10,0.25)$ & $(0.0,0.10,0.25)$ & $(0.0,0.10,0.25)$ & $(0.0,0.10,0.25)$ & $(0.0,0.10,0.25)$ & 4 \\
\hline$(0.0,0.10,0.25)$ & $(0.0,0.10,0.25)$ & $(0.0,0.10,0.25)$ & $(0.0,0.10,0.25)$ & $(0.0,0.10,0.25)$ & $(0.0,0.10,0.25)$ & $(0.0,0.10,0.25)$ & $(0.0,0.10,0.25)$ & 4 \\
\hline$(0.0,0.10,0.25)$ & $(0.0,0.10,0.25)$ & $(0.0,0.10,0.25)$ & $(0.0,0.10,0.25)$ & $(0.0,0.10,0.25)$ & $(0.0,0.10,0.25)$ & $(0.0,0.10,0.25)$ & $(0.0,0.10,0.25)$ & 4 \\
\hline$(0.0,0.10,0.25)$ & $(0.0,0.10,0.25)$ & $(0.0,0.10,0.25)$ & $(0.0,0.10,0.25)$ & $(0.0,0.10,0.25)$ & $(0.0,0.10,0.25)$ & $(0.0,0.10,0.25)$ & $(0.0,0.10,0.25)$ & 4 \\
\hline$(0.0,0.10,0.25)$ & $(0.0,0.10,0.25)$ & $(0.0,0.10,0.25)$ & $(0.0,0.10,0.25)$ & $(0.0,0.10,0.25)$ & $(0.0,0.10,0.25)$ & $(0.0,0.10,0.25)$ & $(0.0,0.10,0.25)$ & 4 \\
\hline$(0.0,0.10,0.25)$ & $(0.0,0.10,0.25)$ & $(0.0,0.10,0.25)$ & $(0.0,0.10,0.25)$ & $(0.0,0.10,0.25)$ & $(0.0,0.10,0.25)$ & $(0.0,0.10,0.25)$ & $(0.01,0.11,0.26)$ & 3 \\
\hline
\end{tabular}




\section{RESULTS AND DISCUSSION}

As we can see in Table 5 that average weights of each criteria has been obtained after pairwise comparison between every two criteria sub criteria. The overall result has been summarized in Table 6 below:

Table 6 Average Weight of Each Criterion

\begin{tabular}{|l|c|c|}
\hline \multicolumn{1}{|c|}{ Criteria } & Average Weight & Rank \\
\hline Quality & $(0.35,0.50,0.65)$ & 1 \\
\hline Technical Capability & $(0.20,0.35,0.50)$ & 2 \\
\hline Buyer Supplier Relation & $(0.00,0.15,0.40)$ & 3 \\
\hline $\begin{array}{l}\text { Production Facility and } \\
\text { Capability }\end{array}$ & $(0.00,0.10,0.25)$ & 4 \\
\hline
\end{tabular}

Table 6 shows that quality is having highest average weight which lies in medium region of Triangular Fuzzy Number (TFN) which dictates that it is most critical criteria for evaluating supplier for their performance. Then comes Technical capability which comes in Low region and likewise.

Table 7 Average Weight of Sub-criteria

\begin{tabular}{|l|c|c|}
\hline Sub Criteria & Average Weight & Rank \\
\hline Product Durability & $(0.00,0.10,0.25)$ & 4 \\
\hline ISO certification status & $(0.10,0.23,0.38)$ & 1 \\
\hline Rejection Rate & $(0.03,0.15,0.30)$ & 2 \\
\hline Design Capability & $(0.00,0.10,0.25)$ & 4 \\
\hline Technology and Innovation & $(0.00,0.10,0.25)$ & 4 \\
\hline $\begin{array}{l}\text { Future Manufacturing facilities and } \\
\text { equipment capabilities }\end{array}$ & $(0.00,0.10,0.25)$ & 4 \\
\hline Facilities for measurement & $(0.00,0.10,0.25)$ & 4 \\
\hline Calibration and Testing & $(0.00,0.10,0.25)$ & 4 \\
\hline Machine Capability & $(0.00,0.10,0.25)$ & 4 \\
\hline Delivery & $(0.00,0.10,0.25)$ & 4 \\
\hline Long Term Relationship & $(0.00,0.10,0.25)$ & 4 \\
\hline Level of trust and understanding & $(0.00,0.10,0.25)$ & 4 \\
\hline Share sensitive information & $(0.01,0.11,0.26)$ & 3 \\
\hline
\end{tabular}

Similarly if make comparison between sub criteria then it is observed that ISO Certification status should be considered the most critical one then rejection rate, share sensitive information and so on. Some sub criteria are having equal ranking so considered the ranking of their corresponding criteria to prioritize them. The Table 8 gives the overall ranking of criteria after considering the individual ranking of each criterion-sub criteria in Table 6 and 7. Thus final ranking shown in Table 8 should be used in this particular manufacturing industry to select the supplier for braking system material for Anti-Compounding relay valve.

Table 8 Final Ranking of Criteria

\begin{tabular}{|l|c|}
\hline Criteria & Rank \\
\hline Quality & 1 \\
\hline Technical Capability & 2 \\
\hline Buyer Supplier Relation & 3 \\
\hline Production Facility and Capability & 4 \\
\hline
\end{tabular}

\section{CONCLUSION}

In this paper a fuzzy AHP approach has been used to select the supplier for braking system material for AntiCompounding relay valve based on the ranking of criteria.
The main criteria and sub criteria have been decided which are based on the current business scenario and experience of the experts in the respective manufacturing firm. The FuzzyAHP approach is proved to be simple, less time taking and having less computational expense as compared to other existing decision making systems. The Fuzzy-AHP has the ability to capture the vagueness of human thinking style and effectively solve multi-attribute decision making problems.

\section{REFERENCES}

Abadi, J.F. and Cordon, C. (2012), Developing a Framework for the Identification and Analysis of the Strategic Resources and Capabilities in Supply Chains, Operations and Supply Chain Management 5 (2), pp. 59-75.

Bello, M.J.S. (2003), A Case Study Approach to the Supplier Selection Process, Management Systems Engineering University of Puerto Rico Mayagüez Campus.

Calvi, R., Dain, M.A.L., Fendt, T.C. and Herrmann, C.J. (2010), Supplier Selection for Strategic Supplier Development, Unité Mixte de Recherche CNRS / Université Pierre Mendès France Grenoble 2150 rue de la Chimie BP 47 - 38040 GRENOBLE cedex 9.

Cebi, F. and Bayraktar, D. (2003), An Integrated Approach for Supplier Selection, Logistics Information Management 16 (6), pp. 395-400.

Chen, Y. J. (2011), Structured Methodology for Supplier Selection and Evaluation in a Supply Chain, Information Sciences 181, pp. 1651 - 1670.

De Boer, L., Labro, E. and Morlacchi, P.(2001), A Review of Methods Supporting Supplier Selection, European Journal of Purchasing and Supply Management 7, pp. $75-89$.

Digalwar, A. K and Metri Bhimaraya A, (2005), Performance Measurement Framework for WorldClass Manufacturing, International Journal of Applied Management and Technology 3 (2), pp.83 - 101.

Digalwar, A. K. and Sangwan, K. S. (2007), Development and Validation of Performance Measures for World Class Manufacturing Practices in India, Journal of Advanced Manufacturing Systems 6 (6), pp.21-38.

Ho, W., Dey, P.K. \& Lockstrom, M. (2011), Strategic sourcing: a Combined QFD and AHP Approach in Manufacturing, Supply Chain Management: An International Journal 16 (6), pp. 446-461.

Jie, J., Cao, G. and Wang, W. (2012), Hybrid Model Using Analytic Network Process and Gray Relational Analysis for Bank's IT Outsourcing Vendor Selection, Kybernetes 41( 7/8), pp. 994-1013.

Khaled,A.A., Paul, S. K., Chakraborty, R. K. and Ayubi, M.S.(2011), Selection of Supplier Through Different Multi Criteria Decision Making Techniques, Global Journal of Management and BusinessResearch 11 (4), pp. 1-13.

Kirytopoulos, K., Leopoulos, V. and Voulgaridou, D. (2008), Supplier Selection in Pharmaceutical Industry an Analytic Network Process Approach, Benchmarking: An International Journal 15 (4), pp. 494-516. 
Koul, S. and Verma, R. (2011), Dynamic Vendor Selection Based on Fuzzy AHP, Journal of Manufacturing Technology Management 22 (8), pp. 963-971.

Kumar, P. and Singh, R.K. (2012), A fuzzy AHP and TOPSIS Methodology to Evaluate 3PL in a Supply Chain, Journal of Modeling in Management 7 (3), pp. 287-303.

Lee, T.R., Le, T.P.N., Genovese, A. and Koh, L.S.C. (2012), Using FAHP to Determine the Criteria for Partner's Selection within a Green Supply Chain, Journal of Manufacturing Technology Management, 23 (1), pp. 25-55.

Mukherjee S. and Kar, S. (2012), Multi Attribute Decision Making Based on Fuzzy Logics and its Application in Supplier Selection Problem, Operations and Supply Chain Management 5 (2), pp. 76-83.
Sennaroglu, B., Sen, S. (2012), Integrated AHP \& TOPSIS Approach for Supplier Selection, $2^{\text {nd }}$ International conference Manufacturing \& Management 2012, pp. 19-22, ISBN 978-80-553-1216-3.

Singh, R. and Sharma S. K. (2011), Supplier Selection: Fuzzy AHP Approach", International Journal of Engineering Science and Technology 3 (10), pp. 74267432.

Tracey, M. and Tan, C.L. (2001), Empirical Analysis of Supplier Selection and Involvement, Customer Satisfaction, and Firm Performance, Supply chain management: An international journal 6 (4), pp. 174188.

Yang, C.C. and Chen, B.S. (2006), Supplier Selection Using Combined Analytical Hierarchy Process and Grey Relational Analysis, Journal of Manufacturing Technology Management 17 (7), pp. 926-941.

\begin{abstract}
Abhijeet K. Digalwar received a Ph.D. from BITS Pilani, India. Presently, he is working as Assistant Professor in Mechanical Engineering. He has over 17 years of teaching and research experience at graduate and post graduate levels. His areas of interest are performance measurement systems, world class manufacturing, total quality management , green manufacturing, knowledge management and manufacturing strategy. He has published more than 50 papers in national and International journals and Conferences. He is life member of Indian Society of Technical Education and a member of Performance Measurement Association, UK and ISDSI of Decision Sciences Institute USA. He is reviewer of many prestigious national and international journals and also working as a editorial board member for International Journal of Manufacturing Systems, Asian Journal of Industrial Engineering and Research Journal of Business Management of Academic Journal inc of USA.
\end{abstract}

Atul Borade received a PhD from Amravati University, India, Presently he is working as a Professor and Head, Mechanical Engineering Department of JDIET Yavatmal. He is also Dean, Research and Development of institute. He has over 17 years of teaching and research experience. His areas of research mainly focus on vendor management, MCDM. He is life member of Indian Society of Technical Education and a member of Performance Measurement Association, UK and ISDSI of Decision Sciences Institute USA. He is reviewer of many prestigious national and international journals and also working as an editorial board member for International Journal of Manufacturing Systems.

Bhimaraya A. Metri received his Ph.D from IIT Bombay, Powai, Mumbai, India. Dr. Metri is currently Dean (Academic) and Professor of operations management at IMI New Delhi. Dr. Metri has more than 24 years of experience in teaching, training, research and consulting. An authority in the field of quality Management, Project Management and supply chain management, Dr. Metri has published over 100 research articles in international, national journals \& proceedings. He is also co-authored books "Managing Global Services" and "World Class Manufacturing". He is on the editorial advisory boards of national and international journals. Dr. Metri served as a member of various National and International Level Committees/forums of higher technical education. He is deeply involved with consulting and executive education including international training with a wide range of organizations including leading organizations of government, public sector and private sector. Apart from global exposure, Dr. Metri has vast experience of National Accreditation-NBA \& International Accreditations-SAQS, AMBA, EQUIS and AACSB. Dr. Metri is the Member of Decision Sciences Institute (DSI), USA. Currently, he is President of the ISDSI and Member Regional Activities Committee, DSI, USA. 